\title{
Long-term Stress of Simply Supported Steel-concrete Composite Beams
}

\author{
Min Ding ${ }^{1,2}$, Xiugen Jiang ${ }^{1}$, Zichen $\operatorname{Lin}^{3}$ and Jinsan Ju ${ }^{1, *}$ \\ ${ }^{1}$ Department of Civil Engineering, China Agricultural University, Beijing 100083, China \\ ${ }^{2}$ Department of Building Engineering, Tongji University, Shanghai 200092, China \\ ${ }^{3}$ School of Soil and Water Conservation, Beijing Forestry University, Beijing 100083, China
}

\begin{abstract}
The theoretical model to compute the long-term stress of simply supported steel-concrete composite beam was deduced. The model includes the effects of steel bars in concrete slab, concrete shrinkage and creep. The computed results agreed well with the test results. On this basis, the effects of factors such as concrete age to loading, longitudinal reinforcement ratio in concrete slab, concrete slab width, steel beam height, environmental yearly average relative humidity, external load value and concrete strength on the long-term stress of steel-concrete composite beams are discussed. The results show that the additional stress at the top of concrete slab is tensile stress and that at the bottom of steel beam is compressive stress. The ratio of steel beam to concrete slab thickness, as well as concrete slab width and the longitudinal reinforcement ratio in concrete slab can not be ignored. Concrete strength, external load value and concrete age to loading have relatively bigger effect as well, But the environmental yearly average relative humidity has less impact. The fruits are useful to the design and application of steel-concrete composite beams.
\end{abstract}

Keywords: Composite beam, long-term stress, factor, analysis.

\section{INTRODUCTION}

Steel-concrete composite beams are a popular and economical form of construction in both buildings and bridges. In a composite beam the steel section is connected to the concrete slab using shear connectors so that they act compositely. This structural arrangement takes advantage of the high tensile strength of steel beam and the high compressive strength of concrete and results in an efficient lightweight beam with a high load-carrying capacity, good ductility and large stiffness. However, the combined effects of concrete creep and shrinkage cause gradual changes in the internal forces and deflection of composite beams under sustained service loads. The internal force changes result in changes of section stress which has effect on concrete creep. Generally, it will raise the deflection and is not good to the structure with high requirement of deflection, finally impact the structure performance.

At the present time, some research studies on long-term performance of steel-concrete composite beam have been carried out and obtained some corresponding achievements. For instance, according to unchanged composite cross section moment at service loads, the formula of long-term rigidity is derived for composite beams under sustained load, in which the effect of creep and shrinkage of concrete is taken into account [1]. The long-term deflection increment was divided into two parts. The deflection induced by creep is based on effective modulus method and the deflection

*Address correspondence to this author at the Department of Civil Engineering, China Agricultural University, Beijing 100083, China; Tel: +86010-62737130 (Office), +86-13552587503 (Mobile); Fax: +86-01062736526; E-mails: jujinsan@tsinghua.org.cn, jujinsan@yahoo.com.cn induced by shrinkage is directly computed [2]. A test program consisting of two simply-supported composite beams under sustained positive bending moment and two cantilever beams under sustained negative bending moment for 1.5 years was carried out [3]. A steel-concrete composite beam was tested under sustained load condition for one year, in a scale of 1:5 to simulate the composite beams in a practical building structure [4]. Four steel-concrete composite beams are tested under sustained load conditions for a period of 500 days, the theoretical model to compute the long-term deflection and stress of composite beams are deduced, and the theoretical computed results agree well with the test results [5]. A serviceability analysis of simply supported composite beams that included the effects of creep and shrinkage in the concrete slab was presented previously [6]. To validate the analytical model, four simply supported composite beams were tested [7]. A second series of long-term tests was undertaken on two-span continuous composite beams subjected to sustained uniformly distributed load on both spans over a period of 340 days [8]. A simplified time-dependent analysis for continuous composite beams with flexible shear connection, subjected to static actions, settlements of the supports, shrinkage, and prestressing of the concrete slab, was proposed [9]. Furthermore, the existing design codes about calculating long-term deflection of steel-concrete composite beam is to multiply a coefficient which is more than 1 with the elastic modular ratio of steel beam to concrete slab.

In this paper, the theoretical model to compute the longterm stress of simply supported steel-concrete composite beams is deduced in combination with the reference [1]. On this basis, the effects of factors from material properties, construction process, section dimension and environment conditions are discussed. It provides technical support and 
data for the design and application of steel-concrete composite beam.

\section{LONG-TERM STRESS MODEL OF STEEL- CONCRETE COMPOSITE BEAM}

The model here is based on the following assumptions:

(1) Shear deformation is ignored.

(2) Slip at the slab-beam interface, between the concrete and any embedded reinforcement, is negligible at service loads.

(3) Concrete stress is not larger than $50 \%$ of the limited strength. And within this range, the creep strain-stress relationship remains linear. It is allowable to superpose strains.

(4) Shrinkage strain keeps the same along the cross section height and the beam length.

(5) Plane sections remain plane; i.e., the strain distribution on any section at any time is linear.

\subsection{The Additional Curvature of Steel-concrete Compos- ite Beam}

The additional curvature of steel-concrete beam refers to the composite section curvature variation within the time period of $\left(t, t_{0}\right)$ under constant sustained load. Where $t$ is the moment to calculate, $t_{0}$ is the moment to loading. Accordingly, the stress variation within the time period of $\left(t, t_{0}\right)$ is additional stress. The analysis model at the time interval $\left(t, t_{0}\right)$ is shown as Fig. (1), where $\Delta N_{\mathrm{c}}, \Delta M_{\mathrm{c}}$ are the self-stressed forces in concrete slab section, respectively the axial force and bending moment; $\Delta N_{\mathrm{s}}, \Delta M_{\mathrm{s}}$ is the self-stressed forces in steel beam section, respectively the axial force and bending moment; $\Delta T_{\mathrm{s} 1}, \Delta T_{\mathrm{s} 2}$ is respectively the constraint selfstressed forces on the concrete slab section due to the steel bar in the bottom and top part of the concrete slab; $h_{\mathrm{c}}$ is the height of concrete slab section; $h_{\mathrm{s}}$ is the height of steel beam section; $h$ is the height of composite section.

(1) The self-stressed forces in the composite section due to the combined effects of concrete shrinkage and creep are self-equilibrium forces.

In the horizontal direction, the equation of force equilibrium can be expressed as

$\Delta N_{s}+\Delta N_{c}+\Delta T_{s 1}+\Delta T_{s 2}=0$

The equation of moment equilibrium in the composite section is given by
$\Delta M_{c}+\Delta N_{c} \frac{h_{c}}{2}+\Delta M_{s}+\Delta N_{s}\left(\frac{h_{s}}{2}+h_{c}\right)+\Delta T_{s 1} y_{s 1}+\Delta T_{s 2} y_{s 2}=0$

Where $y_{\mathrm{s} 1}, y_{\mathrm{s} 2}=$ distance from the bottom and top longitudinal steel bar in the concrete slab to the upper margin of concrete slab, respectively.

(2) Concrete slab and steel beam of the composite beam satisfies with incremental constitutive.

According to the relationship of incremental strain and incremental stress due to concrete shrinkage and creep in Trost-Bazant method [10], the additional strain at the upper margin of concrete slab can be expressed as

$\Delta \varepsilon_{c t}=\varphi \varepsilon_{c e 0}+\varepsilon_{s h}+\frac{\Delta M_{c}}{E_{c}(t) I_{c}} \cdot \frac{h_{c}}{2}-\frac{\Delta N_{c}}{A_{c} E_{c}(t)}$

In the steel beam section, the self-stressed force and increment strain satisfy with elastic constitutive relation of steel. The additional strain at the lower margin of steel beam is given by

$\Delta \varepsilon_{s b}=\frac{\Delta M_{s}}{E_{s} I_{s}} \cdot \frac{h_{s}}{2}+\frac{\Delta N_{s}}{A_{s} E_{s}}$

Where $\varepsilon_{\mathrm{ce} 0}=$ the initial strain at the upper margin of concrete slab section; $\varphi=$ concrete creep coefficient, here according to CEB-FIP 1990; $\varepsilon_{\mathrm{sh}}=$ concrete shrinkage strain, here according to CEB-FIP 1990; $A_{\mathrm{c}}=$ area of concrete slab; $A_{\mathrm{s}}=$ area of steel beam; $E_{\mathrm{c}}(t)=$ age-adjusted elastic modulus of concrete; $E_{\mathrm{s}}=$ elastic modulus of steel beam; $I_{\mathrm{s}}=$ inertia moment of steel beam; $I_{\mathrm{c}}=$ inertia moment of concrete slab.

(3) The steel-concrete composite section satisfies deformation compatibility condition.

The additional curvature due to self-stressed force in the composite beam can be expressed as

$\Delta \phi=\frac{\Delta M_{s}}{E_{s} I_{s}}=\frac{\Delta M_{c}}{E_{c}(t) I_{c}}=\frac{\left(\Delta \varepsilon_{c t}+\Delta \varepsilon_{s b}\right)}{h}$

In the light of the assumption (2), the strain variation of longitudinal steel bar in the concrete slab is equal to the concrete strain variation at the same height with the steel bar, then

$-\frac{\Delta T_{s 1}}{E_{s 1} A_{s 1} s_{r 1}}=\Delta \varepsilon_{c, s 1}=-\frac{\Delta M_{c}}{E_{c}(t) I_{c}} \cdot\left(y_{s 1}-\frac{h_{c}}{2}\right)-\frac{\Delta N_{c}}{E_{c}(t) A_{c}}+\varphi \varepsilon_{c e 0, s 1}+\varepsilon_{s h}$

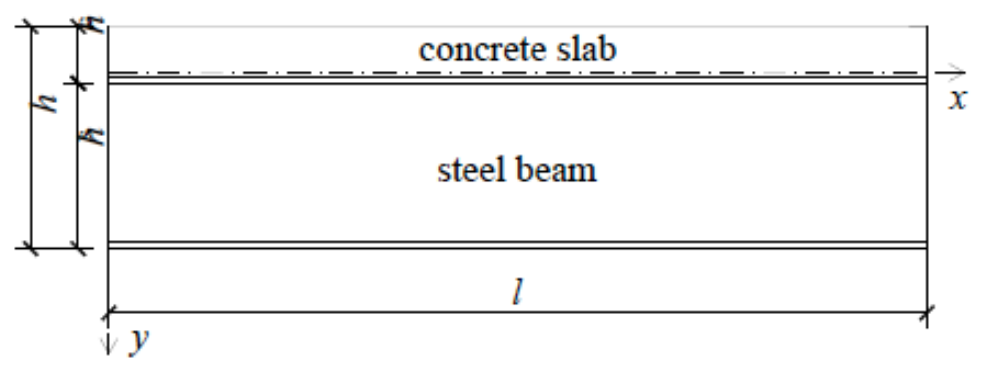

Fig. (1). Analysis model for long-term behavior of steel-concrete composite beam.

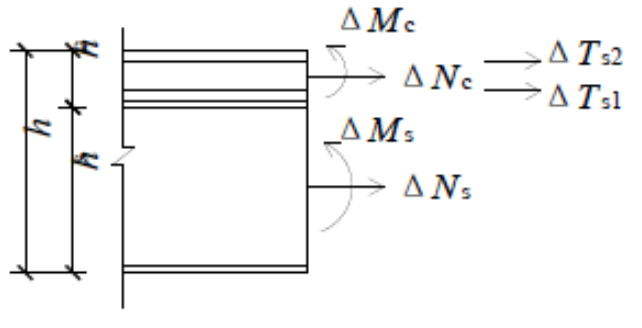




$$
-\frac{\Delta T_{s 2}}{E_{s 2} A_{s 2} s_{r 2}}=\Delta \varepsilon_{c, s 2}=-\frac{\Delta M_{c}}{E_{c}(t) I_{c}} \cdot\left(y_{s 2}-\frac{h_{c}}{2}\right)-\frac{\Delta N_{c}}{E_{c}(t) A_{c}}+\varphi \varepsilon_{c e 0, s 2}+\varepsilon_{s h}
$$

Where $\varepsilon_{\mathrm{ce} 0, \mathrm{~s} 1}, \varepsilon_{\mathrm{ce} 0, \mathrm{~s} 2}=$ the initial concrete strain at the same height with bottom and top part of concrete slab, respectively; $s_{\mathrm{r} 1}, s_{\mathrm{r} 2}=$ reduction coefficient of longitudinal steel bar area ([5] Ding Min 2008).

According to Eqs. (1-7), the additional curvature of composite beam can be expressed as

$$
\Delta \phi=\frac{B \cdot D-C \cdot E}{B \cdot\left(d_{s c}+F\right)-A \cdot E}
$$

Where $d_{\mathrm{sc}}=$ distance from concrete slab axis to steel beam axis; $A, B, C, D, E, F$ are all coefficients depending on section dimension, material properties, and the initial loads, seeing reference [5] in detail.

By substituting Eq. (8) into Eqs. (1-7), the expressions of $\Delta N_{\mathrm{c}}, \Delta M_{\mathrm{c}}, \Delta N_{\mathrm{s}}$ and $\Delta M_{\mathrm{s}}$ are obtained, seeing reference [5] in detail.

\subsection{The Long-term Stress of Steel-concrete Composite Beam}

According to material mechanics, the additional concrete slab stress of steel-concrete composite beam under sustained loads can be expressed as

$\Delta \sigma_{c}=\frac{\Delta M_{c}}{I_{c}} \cdot y_{c}-\frac{\Delta N_{c}}{A_{c}}$

And the additional steel beam stress of that is given by

$\Delta \sigma_{s}=\frac{\Delta M_{s}}{I_{s}} \cdot y_{s}+\frac{\Delta N_{s}}{A_{s}}$

Where $y_{\mathrm{c}}, y_{\mathrm{s}}=$ distance from concrete slab axis, steel beam axis, respectively.

Then the long-term stress of steel-concrete composite beam is expressed as following

Concrete slab stress

$\sigma_{c l}=\sigma_{c}+\Delta \sigma_{c}$

Steel beam stress

Table 1. Parameters $\sigma_{s l}=\sigma_{s}+\Delta \sigma_{s}$

Where $\sigma_{c}, \sigma_{s}=$ initial stress of concrete slab, steel beam, respectively.

The long-term stress of steel-concrete composite beam with consideration of longitudinal steel bar in concrete slab, concrete creep and shrinkage can be calculated from Eq. (11) and Eq. (12). The calculated results agree well with the measured results, seeing reference [5].

\section{DISCUSSION}

From Eq. (11) and Eq. (12), we can found there are many factors effecting the long-term stress of steel-concrete composite beam, including load factors and non-load factors. On the basis of Eq. (11) and Eq. (12), according to the existing research results, the parameters are identified as Table $\mathbf{1}$ so that the effects of these factors on the long-term stress of steel-concrete composite beam are discussed.

According to Fig. (1), the details of the reference composite beam are summarized as follows: the steel beam is I20b, the concrete slab width $b_{\mathrm{c}}$ and thickness $h_{\mathrm{c}}$ are $600 \mathrm{~mm}$ and $100 \mathrm{~mm}$, respectively, the longitudinal reinforcement ratio in concrete slab is $1.0 \%$, the calculation span $l$ is $4800 \mathrm{~mm}$, concrete strength grade is C50, elastic modulus of concrete $E_{\mathrm{c}}$ is $34.5 \mathrm{GPa}$, elastic modulus of steel beam $E_{\mathrm{s}}$ is $206 \mathrm{GPa}$, elastic modulus of longitudinal reinforcement in concrete slab $E_{\mathrm{s}}$ is $210 \mathrm{GPa}$, the external uniform constant load $q$ is $10.8 \mathrm{kN} / \mathrm{m}$, concrete age to load $t_{0}$ is 56 days, and environmental yearly average relative humidity $R H$ is $60 \%$. The ultimate stress of steel-concrete composite beam is defined as the stress at the moment of $t=10000$ days.

\subsection{Effect of Concrete Age to Loading}

It's supposed the concrete age to loading is respectively 14 days, 28 days, 56 days, 90 days, and 120 days. Fig. (2) presents the effects of concrete age to loading on the longterm stress of steel-concrete composite beams. When the concrete age to loading is respectively 14 days, 28 days, 56 days, 90 days, and 120 days, the computed ultimate additional concrete slab stress at the top of mid-span section is respectively $-0.996 \mathrm{MPa},-0.783 \mathrm{MPa},-0.579 \mathrm{MPa},-0.447$ $\mathrm{MPa}$, and $-0.371 \mathrm{MPa}$. The ratio of ultimate stress with initial stress is respectively $0.827,0.864,0.900,0.923$, and

\begin{tabular}{|c|c|c|c|c|c|c|}
\hline Factor & (1) & (2) & (3) & (4) & (5) & (6) \\
\hline Concrete age to loading (days) & 14 & 28 & 56 & 90 & 120 & \\
\hline Concrete slab width (mm) & 300 & 600 & 1200 & 1800 & & \\
\hline Ratio of steel beam height to concrete slab thickness & 2 & 3 & 4 & 5 & & \\
\hline External load value $(\mathrm{kN} / \mathrm{m})$ & 7.2 & 10.8 & 14.4 & & & \\
\hline concrete strength grade & $\mathrm{C} 30$ & $\mathrm{C} 40$ & C50 & C60 & $\mathrm{C} 70$ & $\mathrm{C} 80$ \\
\hline
\end{tabular}
0.936 . The computed ultimate additional steel beam stress at 


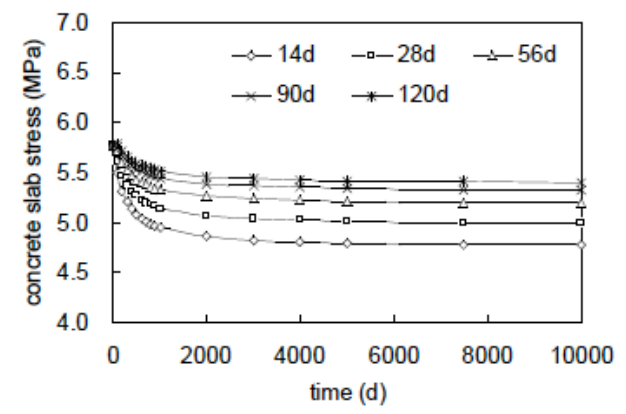

Fig. (2). Effects of concrete age to loading on the long-term stress.

the bottom of mid-span section is respectively $29.807 \mathrm{MPa}$, 26.462 $\mathrm{MPa}, 22.950 \mathrm{MPa}, 20.428 \mathrm{MPa}$, and 18.875 $\mathrm{MPa}$. The ratio of ultimate stress with initial stress is respectively $0.616,0.659,0.704,0.737$, and 0.757 . It can be seen that additional stress at the top of concrete slab is tensile stress and that at the bottom of steel beam is compressive stress. And the longer the concrete age to loading is, the ultimate additional stress will be smaller.

\subsection{Effect of Longitudinal Reinforcement Ratio in Con- crete Slab}

It's supposed the longitudinal reinforcement ratio in concrete slab is respectively $0.0 \%, 0.5 \%, 1.0 \%, 1.5 \%$, and $2.0 \%$. Fig. (3) presents the effects of longitudinal reinforcement ratio on the long-term stress of steel-concrete composite beams. When the longitudinal reinforcement ratio is respectively $0.0 \%, 0.5 \%, 1.0 \%, 1.5 \%$, and $2.0 \%$, the computed ultimate additional concrete slab stress at the top of mid-span section is respectively $-0.136 \mathrm{MPa},-0.426 \mathrm{MPa},-0.683 \mathrm{MPa}$, $-0.912 \mathrm{MPa}$, and $-1.119 \mathrm{MPa}$. The ratio of ultimate stress with initial stress is respectively $0.977,0.928,0.900,0.844$, and 0.808 . The computed ultimate additional steel beam stress at the bottom of mid-span section is respectively

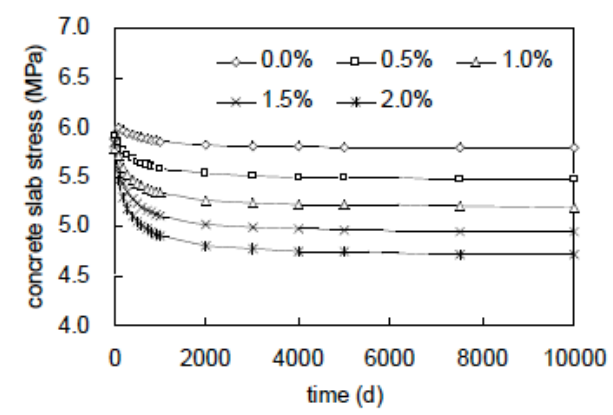

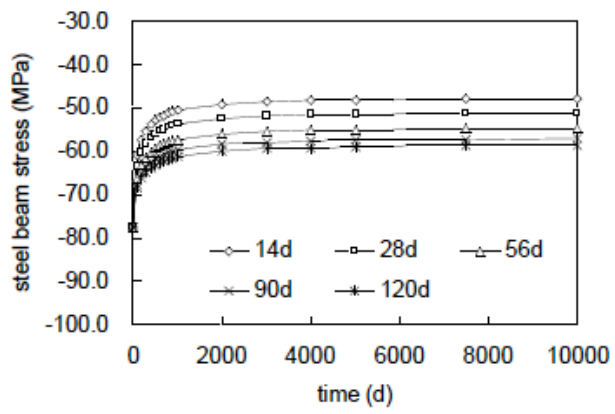

26.194 MPa, 24.504 MPa, 22.950 MPa, 22.510 MPa, and $20.168 \mathrm{MPa}$. The ratio of ultimate stress with initial stress is respectively $0.662,0.684,0.704,0.723$, and 0.740 . It can be seen that additional stress at the top of concrete slab is tensile stress and that at the bottom of steel beam is compressive stress. The larger the longitudinal reinforcement ratio is, the ultimate additional concrete slab stress at the top of midspan section will be larger, and the ultimate additional steel beam stress at the bottom of mid-span section will be smaller. The reason is that the larger longitudinal reinforcement ratio is, the restriction effect of longitudinal reinforcement on concrete shrinkage and creep will be bigger, and then additional concrete slab stress will be larger and additional steel beam stress will be smaller.

\subsection{Effect of Concrete Slab Width}

It's supposed the concrete slab width in concrete slab is respectively $300 \mathrm{~mm}, 600 \mathrm{~mm}, 1200 \mathrm{~mm}$, and $1800 \mathrm{~mm}$. Fig. (4) presents the effects of concrete slab width on the long-term stress of steel-concrete composite beams. When the concrete slab width is respectively $300 \mathrm{~mm}, 600 \mathrm{~mm}$, $1200 \mathrm{~mm}$, and $1800 \mathrm{~mm}$, the computed ultimate additional concrete slab stress at the top of mid-span section is respec-

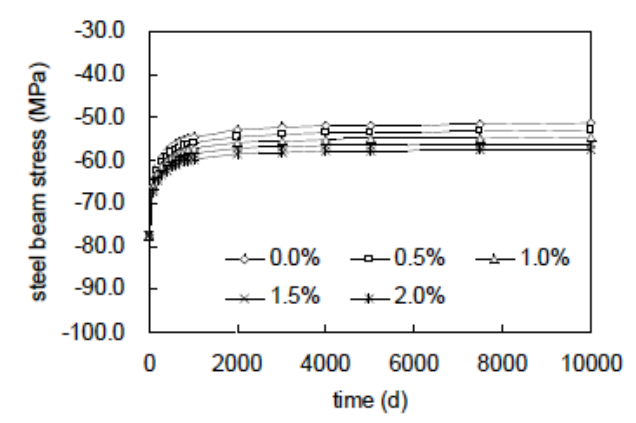

Fig. (3). Effects of longitudinal reinforcement ratio on the long-term stress.
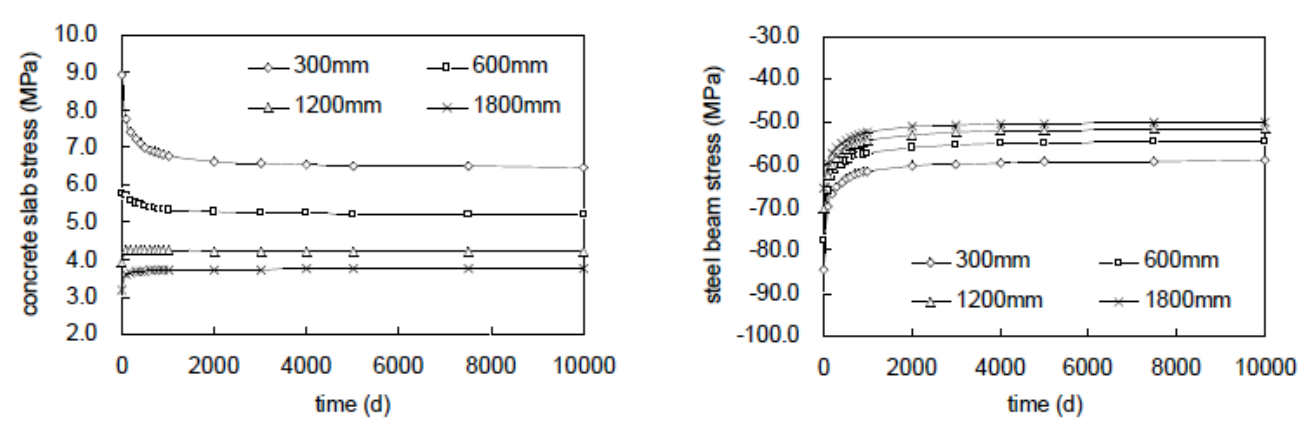

Fig. (4). Effects of concrete slab width on the long-term stress. 
tively -2.464 MPa, $-0.579 \mathrm{MPa}, 0.306 \mathrm{MPa}$, and $0.556 \mathrm{MPa}$. The ratio of ultimate stress with initial stress is respectively $0.727,0.900,1.078$, and 1.175 . The computed ultimate additional steel beam stress at the bottom of mid-span section is respectively 25.505 $\mathrm{MPa}, 22.950 \mathrm{MPa}, 18.920 \mathrm{MPa}$, and $15.702 \mathrm{MPa}$. The ratio of ultimate stress with initial stress is respectively $0.698,0.704,0.732$, and 0.761 . It can be seen that additional stress at the top of concrete slab changes from tensile stress to compressive stress. The additional stress at the bottom of steel beam is compressive stress and its value becomes smaller.

\subsection{Effect of Steel Beam Height}

It's supposed the local buckling of steel beam web will not occur and put the value $R=h_{\mathrm{s}} / h_{\mathrm{c}}$ which is the ratio of steel beam height to concrete slab thickness as $2,3,4$, and 5, respectively. Fig. (5) presents the effects of steel beam height on the long-term stress of steel-concrete composite beams. When the ratio $h_{\mathrm{s}} / h_{\mathrm{c}}$ is respectively $2,3,4$, and 5 , the computed ultimate additional concrete slab stress at the top of mid-span section is respectively $-0.579 \mathrm{MPa},-1.103 \mathrm{MPa}$, $1.334 \mathrm{MPa}$, and $-1.475 \mathrm{MPa}$. The ratio of ultimate stress with initial stress is respectively $0.900,0.679,0.432$, and 0.157 . The computed ultimate additional steel beam stress at the bottom of mid-span section is respectively $22.950 \mathrm{MPa}$, 19.412 $\mathrm{MPa}$, 17.228 $\mathrm{MPa}$, and 15.884 MPa. The ratio of ultimate stress with initial stress is respectively $0.704,0.618$, 0.517 , and 0.401 . It can be seen that additional stress at the top of concrete slab is tensile stress and that at the bottom of steel beam is compressive stress. The larger the ratio $R=h_{\mathrm{s}} / h_{\mathrm{c}}$ is, the ultimate additional concrete slab stress will be larger, and the ultimate steel beam stress will be smaller.

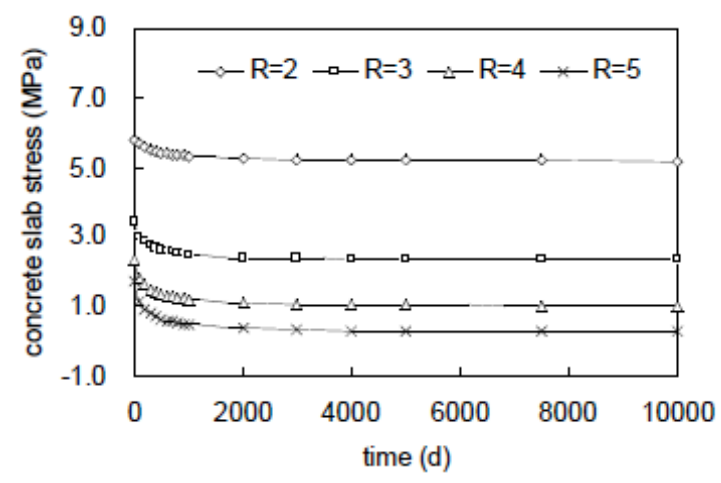

Fig. (5). Effects of steel beam height on the long-term stress.

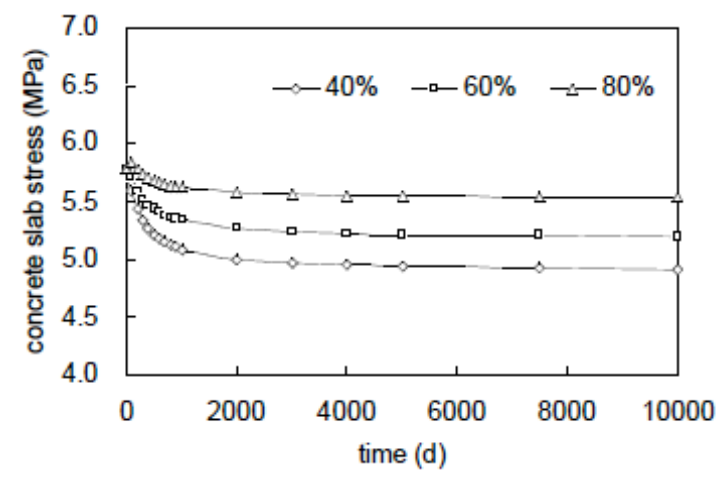

\subsection{Effect of Environmental Yearly Average Relative Humidity}

The environmental yearly average relative humidity $R H$ is one of the key factors effecting the concrete shrinkage and creep. It's supposed the $R H$ respectively is $40 \%, 60 \%$, and $80 \%$. Fig. (6) presents the effects of environmental yearly average relative humidity on the long-term stress of steelconcrete composite beams. When the $R H$ is respectively $40 \%, 60 \%$, and $80 \%$, the computed ultimate additional concrete slab stress at the top of mid-span section is respectively $-0.863 \mathrm{MPa},-0.579 \mathrm{MPa}$, and $-0.244 \mathrm{MPa}$. The ratio of ultimate stress with initial stress is respectively $0.851,0.900$, and 0.958 . The computed ultimate additional steel beam stress at the bottom of mid-span section is respectively 27.402 $\mathrm{MPa}$, 22.950 MPa, and 16.267 MPa. The ratio of ultimate stress with initial stress is respectively $0.647,0.704$, and 0.790 . It can be seen that additional stress at the top of concrete slab is tensile stress and that at the bottom of steel beam is compressive stress. And the larger the $R H$ is, the ultimate additional stress will be smaller.

\subsection{Effect of External Load Value}

It's supposed the external load value is respectively 7.2 $\mathrm{kN} / \mathrm{m}, 10.8 \mathrm{kN} / \mathrm{m}$, and $14.4 \mathrm{kN} / \mathrm{m}$. Fig. (7) presents the effects of external value on the long-term stress of steelconcrete composite beams. When the external load value is respectively $7.2 \mathrm{kN} / \mathrm{m}, 10.8 \mathrm{kN} / \mathrm{m}$, and $14.4 \mathrm{kN} / \mathrm{m}$, the computed ultimate additional concrete slab stress at the top of mid-span section is respectively $-0.525 \mathrm{MPa},-0.579 \mathrm{MPa}$, and $-0.633 \mathrm{MPa}$. The ratio of ultimate stress with initial stress is respectively $0.873,0.900$, and 0.915 . The computed ultimate additional steel beam stress at the bottom of mid-
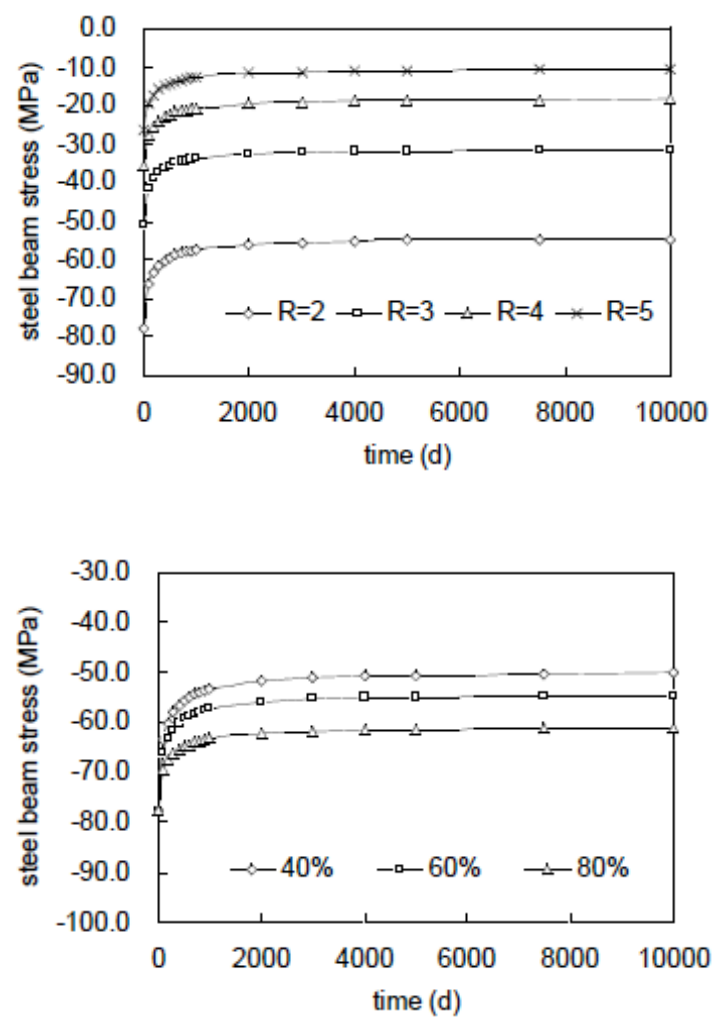

Fig. (6). Effects of environmental yearly average relative humidity on the long-term stress. 

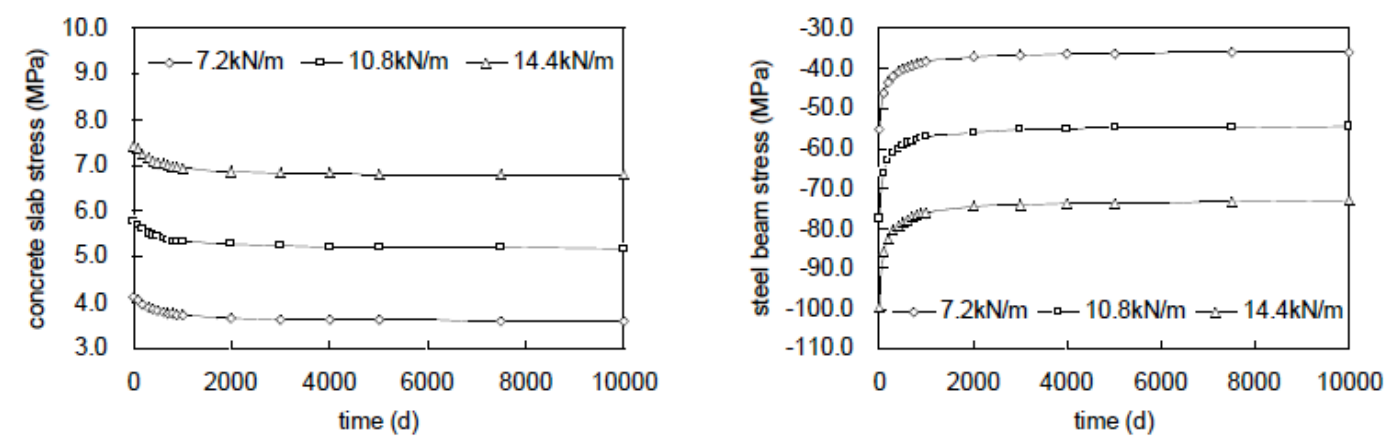

Fig. (7). Effects of external load value on the long-term stress.
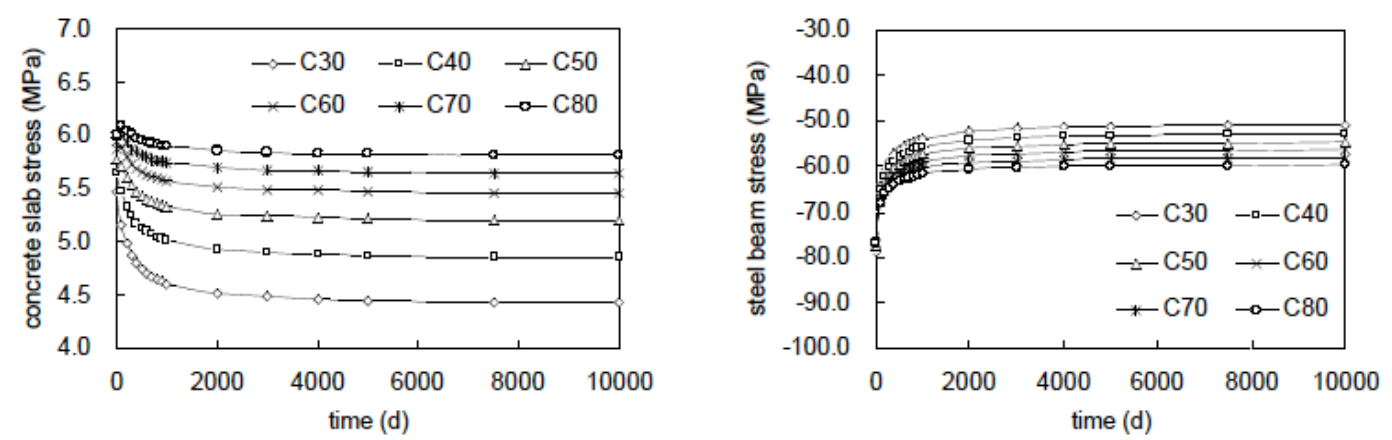

Fig. (8). Effects of concrete strength on the long-term stress.

span section is respectively $19.382 \mathrm{MPa}, 22.950 \mathrm{MPa}$, and $26.517 \mathrm{MPa}$. The ratio of ultimate stress with initial stress is respectively $0.650,0.704$, and 0.734 . It can be seen that additional stress at the top of concrete slab is tensile stress and that at the bottom of steel beam is compressive stress. The larger the external load value is, the ultimate additional stress will be larger.

\subsection{Effect of Concrete Strength}

It's supposed the concrete strength grade is respectively C30, C40, C50, C60, C70, and C80. Fig. (8) presents the effects of concrete strength on the long-term stress of steelconcrete composite beams. When the concrete strength grade is respectively $\mathrm{C} 30, \mathrm{C} 40, \mathrm{C} 50, \mathrm{C} 60, \mathrm{C} 70$, and $\mathrm{C} 80$, the computed ultimate additional concrete slab stress at the top of mid-span section is respectively $-1.042 \mathrm{MPa},-0.785 \mathrm{MPa}$, $0.579 \mathrm{MPa},-0.418 \mathrm{MPa},-0.295 \mathrm{MPa}$, and -0.189 MPa. The ratio of ultimate stress with initial stress is respectively $0.809,0.861,0.900,0.929,0.950$ and 0.969 . The computed ultimate additional steel beam stress at the bottom of midspan section is respectively 28.136 $\mathrm{MPa}, 25.365 \mathrm{MPa}$, 22.950 $\mathrm{MPa}, 20.794 \mathrm{MPa}, 18.842 \mathrm{MPa}$, and 16.991 $\mathrm{MPa}$. The ratio of ultimate stress with initial stress is respectively $0.643,0.675,0.704,0.730,0.755$, and 0.734 . It can be seen that additional stress at the top of concrete slab is tensile stress and that at the bottom of steel beam is compressive stress. The higher the concrete strength is, the ultimate additional stress will be smaller.

\section{CONCLUSIONS}

On the basis of working out the theoretical model to calculate the long-term stress of steel-concrete composite beam regarding the longitudinal reinforcement in concrete slab, concrete shrinkage and concrete creep, the following points

can be concluded after analyzing the key factors effecting the long-term stress of steel-concrete composite beam.

(1) The additional stress at the top of concrete slab is tensile stress and that at the bottom of steel beam is compressive stress.

(2) Among the effecting factors on the long-term stress of steel-concrete composite beam, the ratio of steel beam to concrete slab thickness, as well as concrete slab width and the longitudinal reinforcement ratio in concrete slab can not be ignored. Concrete strength, external load value and concrete age to loading have relatively bigger effect as well. But the environmental yearly average relative humidity has less impact.

\section{ACKNOWLEDGMENTS}

Support for this research by the National Program for New Century Excellent Talents in University No. NCET-080542, the National Natural Science Funds No. 50979108, the Research Start-up Foundation of CAU No. 2008041, Chinese Universities Scientific Fund No. 2009-3-11, and the National Science Support Projects No. 2008BADC4B03.

\section{REFERENCES}

[1] J. G. Nie, "Prediction and analysis for long-term deformation of steel-concrete composite beams", Building Structure, vol. 1, pp. 42-45, January 1997.

[2] H. L. Sun, L.P. Ye, and X. Z. Lu, "Long-term deformation analysis of shrinkage and creep of steel-concrete composite beams", Building Structure, vol. 36, pp. 8-11, June 2006.

[3] J. S. Fan, J. G. Nie, and H. Wang, "Long-term behavior of composite beams with shrinkage, creep and cracking (i): experimental and calculation", China Civil Engineering Journal, vol. 42, pp. 8-15, March 2009.

[4] W. C. Xue, M. Ding, C. He, and J. Li, "Long-term behavior of prestressed composite beams at service loads for one year", Journal of Structural Engineering, vol. 134, pp. 930-937, June 2008. 
[5] M. Ding, The Experimental and Theoretical Studies on Long-term Behavior of Prestressed Steel-concrete Composite Beams, Shanghai, China, Tongji University, September 2008.

[6] M. A. Bradford, "Deflections of composite steel-concrete beams subject to creep and shrinkage", ACI Structural Journal, vol. 88, pp. 610-614, June 1991.

[7] M.A. Bradford, and R. I. Gilbert, "Experiments on composite beams at service loads", Transportation Institution Engineering of Australia Civil Engineering, vol. 33, pp. 285-291, April 1991.
[8] R. I. Gilbert, and M. A. Bradford, "Time-dependent behavior of continuous composite beams at service loads", Journal of Structural Engineering, vol. 121, pp. 319-327, February 1995.

[9] L. Dezi, G. Leoni, and A. M. Tarantino, "Algebraic methods for creep analysis of continuous composite beams", Journal of Structural Engineering, vol. 122, pp. 423-430, April 1996.

[10] L. Zhou, and Y. C. Chen, Shrinkage Creep, Beijing: China Railway Publishing House, 1994.

Received: August 13, 2010

Revised: November 24, 2010

Accepted: December 08, 2010

(C) Ding et al.; Licensee Bentham Open.

This is an open access article licensed under the terms of the Creative Commons Attribution Non-Commercial License (http://creativecommons.org/licenses/by-nc/3.0/) which permits unrestricted, non-commercial use, distribution and reproduction in any medium, provided the work is properly cited. 